\section{(O) OPEN ACCESS}

\title{
Thromboprophylaxis of elderly patients with AF in the UK: an analysis using the General Practice Research Database (GPRD) 2000-2009
}

\author{
Anna C E Scowcroft, ${ }^{1}$ Sally Lee, ${ }^{1}$ Jonathan Mant ${ }^{2}$
}

\begin{abstract}
- Additional supplementary files are published online only. To view these files please visit the journal online (http://dx. doi.org/10.1136/heartjnl-2012302843).

${ }^{1}$ Boehringer Ingelheim, Bracknell, UK

${ }^{2}$ Primary Care Unit, University of Cambridge, Cambridge, UK

\section{Correspondence to}

Professor Jonathan Mant, MA, MSc, MBBS, MD, FFPH,

FRCPEdin Professor of Primary Care Research, University of Cambridge, Strangeways Research Laboratory, Worts Causeway, Cambridge CB1 8RN, UK;

jm677@medschl.cam.ac.uk
\end{abstract}

Received 3 August 2012 Revised 11 September 2012 Accepted 12 September 2012 Published Online First 19 October 2012

To cite: Scowcroft ACE, Lee S, Mant J. Heart 2013, 99, 127-132.

\author{
ABSTRACT \\ Objective To assess use of thromboprophylaxis in UK \\ general practise among patients with atrial fibrillation \\ (AF); to investigate whether elderly patients are less \\ likely to receive anticoagulation therapy than younger \\ patients. \\ Design Retrospective cohort study \\ Setting UK General Practice Research Database (GPRD) \\ Patients Aged $\geq 60$ years with a new diagnosis of AF \\ (2000-2009). \\ Interventions None. \\ Main outcome measures The main outcome
} measure was initiation of warfarin in the first year following diagnosis. Patients were categorised by stroke risk ( $\mathrm{CHADS}_{2}$ score) and bleeding risk (HAS-BLED score). Results 81381 patients were identified (21\% aged 60-69 years, 37\% aged $70-79$ years, $42 \%$ aged $80+$ years). Patients aged $80+$ years were significantly less likely to be initiated on warfarin than younger patients, adjusted for gender, practice and comorbidities; $32 \%$ of patients aged $80+$ years received warfarin compared with $57 \%$ aged $60-69$ years $(p<0.0001)$, and $55 \%$ aged $70-79$ years $(p<0.0001)$. For all strata of $\mathrm{CHADS}_{2} /$ HASBLED scores, patients aged $80+$ years were significantly less likely to be treated with warfarin than younger patients. Logistic regression showed that female sex, low Basal Metabolic Index (BMI), age over 80 years, increasing HAS-BLED score and dementia were independently associated with reduced use of warfarin. Stroke/Transient Ischaemic Attack (TIA), hypertension, heart failure and left ventricular systolic dysfunction were associated with increased use. Patients with HAS$B L E D>C H A D S_{2}$ were less likely to be initiated on warfarin. Higher $\mathrm{CHADS}_{2}$ scores were associated with increased anticoagulation use.

Conclusions Anticoagulation is being under-used in patients with $\mathrm{AF}$ aged $80+$ years, even after taking into account increased bleeding risk in this age group.

\section{INTRODUCTION}

Atrial fibrillation (AF) is the most common cardiac arrhythmia, and is associated with high morbidity and mortality, with stroke being the most significant complication. ${ }^{1} \mathrm{AF}$ increases the risk of stroke 5 -fold, and accounts for around $15 \%$ of all strokes. ${ }^{2}$ While AF can affect adults of any age, the prevalence increases with age: $3.8 \%$ among people aged $>60$ years rising to $9.0 \%$ among those aged $>80$ years. $^{3} \mathrm{AF}$ is a growing problem, projected to increase with the ageing population and the increased survival of patients with chronic cardiac disorders, such as ischaemic heart disease and congestive heart failure (CHF) that predispose to $\mathrm{AF}^{4}$

Oral anticoagulation treatment with a vitamin $\mathrm{K}$ antagonist, traditionally warfarin, has been demonstrated to be highly effective, reducing the relative risk of stroke in patients with $\mathrm{AF}$ by around two-thirds, with a typical absolute annual risk reduction of $2.7 \%{ }^{5}$ Guidelines recommend that the decision to use anticoagulation is primarily based around an assessment of stroke risk in atrial fibrillation. ${ }^{6}$ Older age is recognised as one of the key risk factors. With regard to the two risk stratification schemes in common use, the $\mathrm{CHA}_{2} \mathrm{DS}_{2}$-VASc score recommends that all people in $\mathrm{AF}$ age $\geq 75$ years should be anticoagulated, and the $\mathrm{CHADS}_{2}$ score that anticoagulation is considered for all people in this age group, but is recommended in the presence of an additional risk factor. ${ }^{7}$ However, recent studies have found that warfarin prescription was unrelated to $\mathrm{CHADS}_{2}$ score. $^{8}{ }^{9}$

Recent National Institute for Health \& Clinical Excellence (NICE) guidance recommends use of anticoagulation for all people aged $\geq 75$ years in $\mathrm{AF}^{10}$ Despite this, less than half the patients aged over 80 years receive warfarin among both hospitalised and outpatient populations. ${ }^{10-16}$ A UK study found that between 1994 and 2003, patients with AF aged 85 years and above were five times less likely to be treated with anticoagulants than patients aged $55-64$ years. ${ }^{17}$

Bleeding risk is often cited as a reason for non-use of warfarin among elderly patients, in which case, aspirin is often used as an alternative. ${ }^{11}{ }^{14}$ However, the Warfarin versus Aspirin for Stroke Prevention in Octogenarians with AF (WASPO) trial showed that in patients aged 80-89 years there were significantly more adverse events including bleeding in patients treated with aspirin compared with warfarin. ${ }^{18}$ This is consistent with the Birmingham Atrial Fibrillation Treatment of the Aged (BAFTA) study which found no significant difference in risk of major haemorrhage between warfarin and aspirin in people aged $\geq 75$ years. ${ }^{19}$

In the light of the stronger evidence base for using anticoagulation in the elderly, ${ }^{19}$ the development of scores to quantify bleeding risk in atrial fibrillation, ${ }^{20}$ and the emergence of new anticoagulants, it is timely to examine whether the underuse of anticoagulation in the elderly persists, and the extent to which this can be explained by risk of bleeding. This study sought to examine anticoagulation treatment of elderly patients $(80+$ years) compared with younger 
patients (60-69 years, 70-79 years) within a cohort of patients with AF from the UK population, and to determine the extent to which any differences in treatment prescribing among different age groups might be explained by bleeding risk.

\section{METHODS}

\section{Study design}

This was a cohort study of patients from the General Practice Research Database (GPRD) ${ }^{21}$ with a first diagnosis of AF, between 2000 and 2009. The GPRD includes approximately three million residents in the UK registered with over 600 general practitioners (GPs). The database includes demographics, medical diagnoses, referrals and prescriptions. AF diagnoses were identified using the GPRD Read codes (see appendix 1).

To be eligible, patients had to be flagged as having data of an acceptable quality (as defined by GPRD), and be registered with practices whose data quality met the criteria for an 'up-to-standard' practice. Each patient had to have at least 12 months of data between registering with the practice and their first diagnosis of AF. Patients had to be over the age of 60 years at the time of first diagnosis of AF.

From this cohort, patients who were initiated on warfarin in the year following the AF diagnosis were identified. Warfarin initiation was defined as at least one prescription for warfarin within the first year following AF diagnosis (see appendix 2 for warfarin codes).

\section{Data analysis}

Descriptive statistics were recorded at baseline for the AF cohort at first diagnosis of AF, and for the cohort of patients treated with warfarin at first prescription for warfarin (if within 12 months of diagnosis). Comorbid conditions were defined using GPRD Read codes (see Appendix 1). Patients were split into three age groups: 60-69 years, 70-79 years, and $80+$ years based upon age at AF diagnosis. Differences between groups were tested using $\chi^{2}$ tests, with the group of patients aged $80+$ years as the reference group.

Patients were split between warfarin-treated and warfarinuntreated, based on whether they were initiated on warfarin within their first year following AF diagnosis.

Patients within the AF cohort were categorised into risk groups at baseline using two commonly used risk scores: $\mathrm{CHADS}_{2}$ and $\mathrm{CHA}_{2} \mathrm{DS}_{2}$-VASc. $\mathrm{CHADS}_{2}$ score allocates one point each for CHF, hypertension, age $>75$ years, diabetes mellitus and two points for a prior stroke/TIA. The $\mathrm{CHADS}_{2}$ score was used to stratify patients within the analysis, as this method is most widely used. The $\mathrm{CHA}_{2} \mathrm{DS}_{2}$-VASc score incorporates the additional risk factors of vascular disease, age 65-74 years, and female gender, and gives two points each to age $\geq 75$ years and prior stroke/TIA/ thromboembolism, and one point each to all other factors.

The HAS-BLED score (hypertension, abnormal renal/liver function, stroke, bleeding history or predisposition, labile international normalised ratio (INR), elderly (>65 years), drugs/ alcohol) is recommended to assess the bleeding risk of patients with AF when deciding whether to prescribe anticoagulation. ${ }^{22}$ Hypertension was defined as a diagnosis of hypertension, or a systolic blood pressure reading of at least $160 \mathrm{mmHg}$ in the last year. Abnormal renal function required a patient to have a Read code for chronic dialysis, renal transplant, chronic kidney disease stage 5 , or a serum creatinine level of $200 \mathrm{mmol} / \mathrm{l}$ or above. Abnormal liver function included chronic hepatic disease, cirrhosis or significant hepatic derangement. Bleeding history or predisposition was defined as patients with a record of a serious bleed or anaemia in the previous year, and a labile INR required that the patient was prescribed warfarin in the year prior to AF diagnosis, and had a time in therapeutic range lower than $60 \%$ in that year. Drugs refer to Non-steroidal Antiinflammatory Drugs (NSAID) or antiplatelet use, and patients were allocated one point if they had at least two prescriptions for either of these in the latest year, and another point for a diagnosis of alcoholism in the latest year.

Pisters et al proposed that if HAS-BLED score is greater than $\mathrm{CHADS}_{2}$ score in patients with $\mathrm{CHADS}_{2} \geq 2$, then anticoagulation should not be given due to risk of bleeding. ${ }^{22}$ The percentage of patients treated with warfarin in each age group was split by HAS-BLED $>\mathrm{CHADS}_{2}$ and HAS-BLED $\leq \mathrm{CHADS}_{2}$.

Logistic regression was used to identify the factors which affected whether patients were initiated on warfarin. Results were found to be significantly different between sexes, so men and women were modelled separately in order to produce clinically useful estimates. The results were adjusted for practice, to take into account differential prescribing practices between practices, as well as regional variation, by including dummy variables for each practice in the model. Logistic regression models were fitted using SAS software, V.9.2 (SAS Institute Inc, Cary, North Carolina, USA) using PROC LOGISTIC.

Further logistic regression models were used to investigate whether stroke risk (measured using CHADS2 score) had an effect on whether men and women were treated with warfarin, adjusted for age and practice.

\section{RESULTS \\ Patients}

A cohort of 81381 patients with AF was identified, of whom 17054 (21\%) were aged 60-69 years, 30350 (37\%) were aged $70-79$ years, and 33977 (42\%) were aged $80+$ years. Just over half the cohort $(52 \% ; n=42318)$ were women. More patients with $\mathrm{AF}$ were female in the older age group ( $\geq 80$ years; $63 \%$ female), while patients in the youngest age group were predominantly men (60-69 years; 63\% male) (table 1).

\section{Warfarin treatment}

Patients aged $80+$ years were significantly less likely to be initiated on warfarin in the first year following AF diagnosis than younger patients; $32 \%$ of patients aged $80+$ years received warfarin compared with 55\% aged 70-79 years, $\chi^{2}(1, \mathrm{n}=64327)=3453(\mathrm{p}<0.0001)$, and $57 \%$ aged $60-69$ years, $\chi^{2}(1, \mathrm{n}=51031)=2883 \quad(\mathrm{p}<0.0001) \quad($ table 1$)$. This remained true in all subgroups of patients with comorbidities. Men were more likely to be initiated on warfarin than women in all age groups (table 1).

Over the 10-year study period (2000-2009), there was a trend towards increased prescribing of warfarin in patients with $\mathrm{AF}$, which was consistent across the three age groups. The proportion of patients aged $80+$ years initiated on warfarin following AF diagnosis increased from 25\% to 37\% between 2000 and 2009 , but was still much lower than the proportion in younger patients $(48 \%$ to $61 \%$ in patients aged $70-79$ years, and $54 \%$ to $55 \%$ in patients aged $60-69$ years).

Logistic regression models of whether warfarin was initiated in the year following AF diagnosis are presented (table 2). For both men and women, age was the strongest independent predictor of warfarin use. A patient aged 60-69 years, or 70-79 years, was more than twice as likely to be initiated on warfarin following a diagnosis of $\mathrm{AF}$, than a patient with the same BMI, gender and comorbidities aged $\geq 80$ years (table 2). Having adjusted for other factors, patients with BMI $<20 \mathrm{~kg} / \mathrm{m}^{2}$ were significantly less likely to receive warfarin treatment than patients with BMI $20-25 \mathrm{~kg} / \mathrm{m}^{2}$. Patients with higher BMIs were 
Table 1 Frequency of comorbidities in total atrial fibrillation patient population and among those treated with warfarin

\begin{tabular}{|c|c|c|c|c|c|c|c|c|c|c|c|}
\hline \multirow[b]{2}{*}{ Age group } & \multirow[b]{2}{*}{$\begin{array}{l}\text { All patients } \\
\mathbf{n}(\%)\end{array}$} & \multicolumn{4}{|l|}{$60-69$ years } & \multicolumn{4}{|l|}{ 70-79 years } & \multicolumn{2}{|c|}{$80+$ years (reference group) } \\
\hline & & $\begin{array}{l}\text { Patients n } \\
(\%)\end{array}$ & $\begin{array}{l}\text { Patients } \\
\text { treated } \\
\text { with } \\
\text { warfarin n } \\
(\%)\end{array}$ & $\begin{array}{l}\chi^{2} \\
\text { Value* }\end{array}$ & $\begin{array}{l}\text { p } \\
\text { Value* }\end{array}$ & $\begin{array}{l}\text { Patients n } \\
(\%)\end{array}$ & $\begin{array}{l}\text { Patients } \\
\text { treated } \\
\text { with } \\
\text { warfarin n } \\
(\%)\end{array}$ & $\begin{array}{l}\chi^{2} \\
\text { Valuet }\end{array}$ & $\begin{array}{l}p \\
\text { Valuet }\end{array}$ & Patients $\mathbf{n}(\%)$ & $\begin{array}{l}\text { Patients } \\
\text { treated with } \\
\text { warfarin n (\%) }\end{array}$ \\
\hline Number of patients & 81381 & 17054 & $9648(57)$ & 2883 & $<0.0001$ & 30350 & $16641(55)$ & 3453 & $<0.0001$ & 33977 & $10830(32)$ \\
\hline Women & $42318(52)$ & $6300(37)$ & $3268(52)$ & 1094 & $<0.0001$ & $14315(47)$ & $7433(52)$ & 1849 & $<0.0001$ & $21300(63)$ & $6246(29)$ \\
\hline Men & $39063(48)$ & $10754(63)$ & $6380(59)$ & 1254 & $<0.0001$ & $16035(53)$ & $9208(57)$ & 1283 & $<0.0001$ & $12677(37)$ & $4584(36)$ \\
\hline BMI, mean (SD) & $27.1(5.2)$ & $29.0(5.9)$ & $29.5(6.1)$ & & & $27.6(5.2)$ & $28.0(5.2)$ & & & $25.8(4.7)$ & $26.5(4.6)$ \\
\hline$\%$ with non-missing BMI & & 85 & 87 & & & 74 & 87 & & & 74 & 82 \\
\hline Hypertension (diagnosed) & $44841(55)$ & 8362 (49) & 4951 (59) & 1461 & $<0.0001$ & $17328(57)$ & $9692(56)$ & 1694 & $<0.0001$ & $19151(56)$ & $6603(34)$ \\
\hline Diabetes & $10022(12)$ & $2233(13)$ & $1333(60)$ & 377 & $<0.0001$ & 4291 (14) & $2358(55)$ & 355 & $<0.0001$ & $3498(10)$ & 1175 (34) \\
\hline LVEF $<40 \%$ & $2719(3)$ & $723(4)$ & $529(73)$ & 109 & $<0.0001$ & $1165(4)$ & $797(68)$ & 92 & $<0.0001$ & $831(2)$ & 391 (47) \\
\hline Coronary heart disease & $19860(2)$ & $3531(2)$ & $2088(59)$ & 588 & $<0.0001$ & $8052(27)$ & $4592(57)$ & 794 & $<0.0001$ & $8277(24)$ & 2901 (35) \\
\hline Congestive heart failure & $21075(26)$ & $3094(18)$ & $2152(70)$ & 1277 & $<0.0001$ & 7401 (24) & $4490(61)$ & 1296 & $<0.0001$ & $10580(31)$ & 3549 (34) \\
\hline Stroke & $8142(10)$ & $1264(7)$ & $807(64)$ & 369 & $<0.0001$ & $3084(10)$ & $1760(57)$ & 394 & $<0.0001$ & 3794 (11) & 1259 (33) \\
\hline Stroke/TIA & $10763(13)$ & $1567(9)$ & $1029(66)$ & 496 & $<0.0001$ & $3928(13)$ & $2299(59)$ & 543 & $<0.0001$ & $5268(16)$ & 1797 (34) \\
\hline Alzheimer's/dementia & $5382(7)$ & $187(1)$ & $95(51)$ & 121 & $<0.0001$ & $1519(5)$ & $617(41)$ & 294 & $<0.0001$ & $3676(11)$ & $664(18)$ \\
\hline Thromboembolism $\ddagger$ & $4619(6)$ & $803(5)$ & $554(69)$ & 132 & $<0.0001$ & $1729(6)$ & 1109 (64) & 137 & $<0.0001$ & $2087(6)$ & $943(45)$ \\
\hline Vascular disease $\ddagger$ & $12389(15)$ & $2225(13)$ & $1353(61)$ & 418 & $<0.0001$ & 4997 (16) & $2847(57)$ & 487 & $<0.0001$ & $5167(15)$ & $1816(35)$ \\
\hline \multicolumn{12}{|l|}{$\mathrm{CHADS}_{2}$ score } \\
\hline 0 & $10241(13)$ & $6243(37)$ & 3072 (49) & - & - & 3998 (13) & $2038(51)$ & - & - & $0(0)$ & $0(0)$ \\
\hline 1 & 24859 (31) & 6701 (39) & 3925 (59) & 1514 & $<0.0001$ & $9865(33)$ & $5297(54)$ & 1310 & $<0.0001$ & $8293(24)$ & $2249(27)$ \\
\hline $2+$ & 46281 (57) & $4110(24)$ & $2651(65)$ & 1458 & $<0.0001$ & $16487(56)$ & $9306(56)$ & 2181 & $<0.0001$ & $25684(76)$ & 8581 (33) \\
\hline \multicolumn{12}{|l|}{$\mathrm{CHA}_{2} \mathrm{DS}_{2}$-VASc score } \\
\hline 0 & $1620(2)$ & $1620(9)$ & $798(49)$ & - & - & $0(0)$ & $0(0)$ & - & - & $0(0)$ & $0(0)$ \\
\hline 1 & $6276(8)$ & $4348(25)$ & $2292(53)$ & - & - & $1928(6)$ & $1028(53)$ & - & - & $0(0)$ & $0(0)$ \\
\hline $2+$ & $73485(90)$ & $11086(65)$ & $6558(59)$ & 2625 & $<0.0001$ & $28422(94)$ & $15613(55)$ & 3370 & $<0.0001$ & $33977(100)$ & $10830(32)$ \\
\hline \multicolumn{12}{|l|}{ HAS-BLED } \\
\hline $0-1$ & 31522 (39) & 10337 (61) & 5805 (56) & 1169 & $<0.0001$ & 10445 (34) & $5857(56)$ & 1167 & $<0.0001$ & 10740 (32) & 3518 (33) \\
\hline $2+$ & $49859(61)$ & 6717 (39) & $3843(57)$ & 1478 & $<0.0001$ & $19905(66)$ & $10784(54)$ & 2271 & $<0.0001$ & 23237 (68) & 7312 (31) \\
\hline
\end{tabular}

increasingly likely to be treated with warfarin than patients with BMI $20-25 \mathrm{~kg} / \mathrm{m}^{2}$. Increasing bleeding risk, as measured using HAS-BLED score, reduced the probability that a patient was treated with warfarin.

In men and women, hypertension, heart failure, reduced left ventricular ejection fraction, thromboembolism and a history of stroke or TIA, all independently increased the likelihood that a patient received warfarin. Paradoxically, men with diabetes were less likely to be anticoagulated, and presence of diabetes was not associated with use of anticoagulation in women. In both sexes, dementia halved the chance that warfarin was used.

\section{Stroke and bleeding risk analysis}

As would be anticipated, $\mathrm{CHADS}_{2}$ scores rise with age, with $76 \%$ of patients aged $80+$ years having a $\mathrm{CHADS}_{2}$ score of 2 or above compared with $56 \%$ of patients aged $70-79$ years, and $24 \%$ of patients aged $60-69$ years.

Patients in the $80+$ years age group had higher HAS-BLED scores than patients aged $60-69$ years; $68 \%$ of patients aged $80+$ years had a HAS-BLED score $\geq 2$ compared with $39 \%$ of patients aged 60-69 years (and 66\% patients aged 70-79 years) (table 1 ).

Patients with HAS-BLED $>\mathrm{CHADS}_{2}$ were slightly less likely to be initiated on warfarin. This effect was greater in patients with $\mathrm{CHADS}_{2} \geq 2$, and in patients aged 60-69 years (table 3). For all strata of $\mathrm{CHADS}_{2} / \mathrm{HAS}$-BLED scores in table 3 (bar one, due to small numbers), patients in the $80+$ years age group were significantly less likely to be treated with warfarin than those of younger ages.

Logistic regression models investigating $\mathrm{CHADS}_{2}$ (table 4) found evidence in both men and women of a significant increase in the chance of being prescribed warfarin as $\mathrm{CHADS}_{2}$ score increased, when adjusted for age group and practice.

\section{DISCUSSION}

Patients with AF, aged 80 years or over, are much less likely to be treated with warfarin than younger patients. This holds true if the data are adjusted to take into account factors that might deter a clinician from prescribing warfarin, such as frailty (indicated by low BMI), bleeding risk and Alzheimer's disease. While the proportion of people over 80 years treated with warfarin has increased moderately over the study period (2000-2009), it remains substantially lower than the proportion treated in the younger age groups. Logistic regression analysis demonstrated that a patient aged $60-79$ years is more than twice as likely to be initiated on warfarin following a diagnosis of AF, than a patient with the same gender, BMI, comorbidities and bleeding risk aged over 80 years (table 2 ).

Our finding of low warfarin use among elderly patients in the UK is consistent with findings of US studies in hospitals and in primary care, which found warfarin prescribed in only 
Table 2 Logistic regression models

\begin{tabular}{|c|c|c|c|c|c|c|}
\hline Variable & Unadjusted OR§ & $95 \% \mathrm{Cl}$ & p Value & Adjusted OR§ & $95 \% \mathrm{Cl}$ & p Value \\
\hline \multicolumn{7}{|l|}{ Men } \\
\hline Age $60-69 *$ & 2.55 & 2.4 to 2.72 & $<0.0001$ & 2.15 & 2.01 to 2.29 & $<0.0001$ \\
\hline Age $70-79^{*}$ & 2.32 & 2.19 to 2.45 & $<0.0001$ & 2.20 & 2.08 to 2.33 & $<0.0001$ \\
\hline $\mathrm{BMI}<20 \dagger$ & 0.56 & 0.49 to 0.65 & $<0.0001$ & 0.60 & 0.52 to 0.70 & $<0.0001$ \\
\hline BMI $25-<30 \dagger$ & 1.43 & 1.35 to 1.51 & $<0.0001$ & 1.30 & 1.23 to 1.38 & $<0.0001$ \\
\hline BMI $30-<35 t$ & 1.75 & 1.63 to 1.87 & $<0.0001$ & 1.46 & 1.36 to 1.57 & $<0.0001$ \\
\hline BMI $35+\dagger$ & 2.30 & 2.07 to 2.55 & $<0.0001$ & 1.73 & 1.55 to 1.93 & $<0.0001$ \\
\hline Hypertension & 1.17 & 1.11 to 1.22 & $<0.0001$ & 1.24 & 1.18 to 1.3 & $<0.0001$ \\
\hline Heart Failure & 1.34 & 1.27 to 1.41 & $<0.0001$ & 1.41 & 1.33 to 1.49 & $<0.0001$ \\
\hline LVEF & 2.09 & 1.86 to 2.35 & $<0.0001$ & 1.72 & 1.52 to 1.94 & $<0.0001$ \\
\hline Diabetes & 1.08 & 1.01 to 1.15 & $<0.0001$ & 0.94 & 0.88 to 1.00 & 0.05650 \\
\hline Stroke/TIA & 1.15 & 1.07 to 1.23 & $<0.0001$ & 1.56 & 1.44 to 1.68 & $<0.0001$ \\
\hline Dementia & 0.47 & 0.42 to 0.53 & $<0.0001$ & 0.59 & 0.52 to 0.66 & $<0.0001$ \\
\hline Vascular Disease & 1.10 & 1.04 to 1.17 & 0.0006 & 1.10 & 1.03 to 1.16 & 0.00260 \\
\hline Thromboembolism & 1.59 & 1.44 to 1.76 & $<0.0001$ & 1.59 & 1.44 to 1.77 & $<0.0001$ \\
\hline HAS-BLED 2 & 0.82 & 0.78 to 0.87 & $<0.0001$ & 0.8 & 0.76 to 0.85 & $<0.0001$ \\
\hline HAS-BLED 3 & 0.69 & 0.65 to 0.74 & $<0.0001$ & 0.612 & 0.57 to 0.66 & $<0.0001$ \\
\hline \multirow[t]{2}{*}{ HAS-BLED 4} & 0.55 & 0.5 to 0.61 & $<0.0001$ & 0.432 & 0.38 to 0.49 & $<0.0001$ \\
\hline & $\mathrm{p}$ & & & & & \\
\hline Goodness-of-fitł & 0.79 & & & & & \\
\hline \multicolumn{7}{|l|}{ Women } \\
\hline Age $60-69 *$ & 2.29 & 2.14 to 2.44 & $<0.0001$ & 1.95 & 1.82 to 2.10 & $<0.0001$ \\
\hline Age $70-79^{*}$ & 2.43 & 2.31 to 2.55 & $<0.0001$ & 2.29 & 2.17 to 2.41 & $<0.0001$ \\
\hline $\mathrm{BMI}<20 \dagger$ & 0.63 & 0.58 to 0.70 & $<0.0001$ & 0.69 & 0.62 to 0.76 & $<0.0001$ \\
\hline BMI 25-<30† & 1.35 & 1.28 to 1.43 & $<0.0001$ & 1.25 & 1.18 to 1.32 & $<0.0001$ \\
\hline BMI $30-<35 t$ & 1.55 & 1.45 to 1.66 & $<0.0001$ & 1.33 & 1.24 to 1.42 & $<0.0001$ \\
\hline BMI 35+† & 1.96 & 1.81 to 2.13 & $<0.0001$ & 1.46 & 1.34 to 1.59 & $<0.0001$ \\
\hline Hypertension & 1.14 & 1.09 to 1.19 & $<0.0001$ & 1.23 & 1.17 to 1.3 & $<0.0001$ \\
\hline Heart Failure & 1.18 & 1.12 to 1.24 & $<0.0001$ & 1.28 & 1.21 to 1.35 & $<0.0001$ \\
\hline LVEF & 1.82 & 1.58 to 2.11 & $<0.0001$ & 1.55 & 1.33 to 1.80 & $<0.0001$ \\
\hline Diabetes & 1.00 & 0.94 to 1.07 & 0.93 & Not included in final model & & \\
\hline Stroke/TIA & 1.16 & 1.08 to 1.24 & $<0.0001$ & 1.49 & 1.38 to 1.60 & $<0.0001$ \\
\hline Dementia & 0.41 & 0.37 to 0.46 & $<0.0001$ & 0.51 & 0.46 to 0.57 & $<0.0001$ \\
\hline Vascular disease & 0.96 & 0.89 to 1.03 & 0.22 & Not included in final model & & \\
\hline Thromboembolism & 1.74 & 1.58 to 1.91 & $<0.0001$ & 1.72 & 1.56 to 1.90 & $<0.0001$ \\
\hline HAS-BLED 2 & 0.85 & 0.81 to 0.9 & $<0.0001$ & 0.83 & 0.79 to 0.88 & $<0.0001$ \\
\hline HAS-BLED 3 & 0.78 & 0.73 to 0.83 & $<0.0001$ & 0.71 & 0.66 to 0.76 & $<0.0001$ \\
\hline \multirow[t]{2}{*}{ HAS-BLED 4} & 0.61 & 0.55 to 0.68 & $<0.0001$ & 0.51 & 0.45 to 0.57 & $<0.0001$ \\
\hline & $\mathrm{p}$ & & & & & \\
\hline Goodness-of-fit $\ddagger$ & 0.43 & & & & & \\
\hline
\end{tabular}

${ }^{*}$ Age: reference group=Age $80+$ years;

†BMI: reference group $=\mathrm{BMI} 20-<25$;

‡Hosmer and Lemeshow goodness-of-fit test.

$\S \mathrm{OR}$, unadjusted is crude OR adjusted for practice only, adjusted is OR from multivariable model adjusted for practice and all other variables included in the final model.

$40 \%-45 \%$ of patients with $\mathrm{AF}$, with age increasing the risk of not being treated. ${ }^{11-14}$ Our findings are also consistent with an earlier analysis of patients with AF from the GPRD database in 1996 that found among potential candidates for anticoagulation, only $22 \%$ of those aged $70+$ years were prescribed warfarin compared with $49 \%$ among patients aged $40-60$ years. $^{23}$ While a trend towards increasing warfarin prescribing practice in recent years has been demonstrated in our study, the results show that current prescribing practice is not in step with the current evidence base, and that anticoagulation therapy is particularly under-used in elderly patients. This is important, since there is now a clear evidence base that anticoagulation is effective for stroke prevention in elderly people in atrial fibrillation. ${ }^{19}$ Indeed, a recent non-randomised study found that warfarin use in this age group not only was associated with reduced stroke risk, but also with improved life expectancy. ${ }^{9}$

This study found that in the UK, women with AF are less likely to be prescribed warfarin than men with the same risk factors for stroke, even though female sex has been associated with increased risk of stroke in $\mathrm{AF}^{4}$ This is consistent with findings in Scotland that women with AF were 25\% less likely to receive warfarin than men, ${ }^{24}$ and a Canadian study which showed that women were 54\% less likely to receive warfarin, but only in the subgroup of patients aged $\geq 75$ years. $^{25}$ However, a more recent Canadian study found no evidence of reduced usage of warfarin in women compared with men. ${ }^{26}$

It is difficult to explain the disparity of use of anticoagulation in women as compared with men. Gender inequalities have been 
Table 3 Warfarin treatment by HAS-BLED and CHADS2 score

\begin{tabular}{|c|c|c|c|c|c|c|c|c|c|c|c|}
\hline \multirow[b]{2}{*}{$\mathrm{CHADS}_{2}$} & \multirow[b]{2}{*}{ Age group } & \multicolumn{4}{|c|}{$60-69$ years } & \multicolumn{4}{|c|}{$70-79$ years } & \multicolumn{2}{|c|}{$\begin{array}{l}80+\text { years (reference } \\
\text { group) }\end{array}$} \\
\hline & & $\begin{array}{l}\text { Patients } \\
\text { n }\end{array}$ & $\begin{array}{l}\text { Patients treated } \\
\text { with warfarin } \\
(\%)\end{array}$ & $\begin{array}{l}\chi^{2} \\
\text { Value* }\end{array}$ & $\begin{array}{l}\mathrm{p} \\
\text { Value* }\end{array}$ & $\begin{array}{l}\text { Patients } \\
\text { n }\end{array}$ & $\begin{array}{l}\text { Patients treated } \\
\text { with warfarin } \\
(\%)\end{array}$ & $\begin{array}{l}\chi^{2} \\
\text { Valuet }\end{array}$ & $\begin{array}{l}p \\
\text { Valuet }\end{array}$ & $\begin{array}{l}\text { Patients } \\
\mathrm{n}\end{array}$ & $\begin{array}{l}\text { Patients treated } \\
\text { with warfarin } \\
(\%)\end{array}$ \\
\hline 0 & $\begin{array}{l}\text { HAS-BLED }>\mathrm{CHADS}_{2} \\
\text { HAS-BLED } \leq \mathrm{CHADS}_{2}\end{array}$ & $\begin{array}{l}4265 \\
1978\end{array}$ & $\begin{array}{l}49 \\
49\end{array}$ & - & - & $\begin{array}{r}3998 \\
0\end{array}$ & $\begin{array}{l}51 \\
-\end{array}$ & - & - & $\begin{array}{l}0 \\
0\end{array}$ & - \\
\hline 1 & $\begin{array}{l}\text { HAS-BLED }>\text { CHADS }_{2} \\
\text { HAS-BLED } \leq \text { CHADS }_{2}\end{array}$ & $\begin{array}{l}2880 \\
3821\end{array}$ & $\begin{array}{l}56 \\
60\end{array}$ & $\begin{array}{l}692 \\
814\end{array}$ & $\begin{array}{l}<0.0001 \\
<0.0001\end{array}$ & $\begin{array}{l}5556 \\
4309\end{array}$ & $\begin{array}{l}52 \\
56\end{array}$ & $\begin{array}{l}697 \\
640\end{array}$ & $\begin{array}{l}<0.0001 \\
<0.0001\end{array}$ & $\begin{array}{l}3801 \\
4492\end{array}$ & $\begin{array}{l}25 \\
29\end{array}$ \\
\hline 2 & $\begin{array}{l}\text { HAS-BLED }>\mathrm{CHADS}_{2} \\
\text { HAS-BLED } \leq \mathrm{CHADS}_{2}\end{array}$ & $\begin{array}{r}512 \\
2137\end{array}$ & $\begin{array}{l}55 \\
65\end{array}$ & $\begin{array}{l}130 \\
772\end{array}$ & $\begin{array}{l}<0.0001 \\
<0.0001\end{array}$ & $\begin{array}{l}2296 \\
6997\end{array}$ & $\begin{array}{l}52 \\
58\end{array}$ & $\begin{array}{r}266 \\
1022\end{array}$ & $\begin{array}{l}<0.0001 \\
<0.0001\end{array}$ & $\begin{array}{r}3286 \\
10596\end{array}$ & $\begin{array}{l}30 \\
33\end{array}$ \\
\hline 3 & $\begin{array}{l}\text { HAS-BLED }>\mathrm{CHADS}_{2} \\
\text { HAS-BLED } \leq \mathrm{CHADS}_{2}\end{array}$ & $\begin{array}{l}128 \\
965\end{array}$ & $\begin{array}{l}52 \\
69\end{array}$ & $\begin{array}{r}31 \\
419\end{array}$ & $\begin{array}{l}<0.0001 \\
<0.0001\end{array}$ & $\begin{array}{r}419 \\
4157\end{array}$ & $\begin{array}{l}53 \\
58\end{array}$ & $\begin{array}{r}71 \\
554\end{array}$ & $\begin{array}{l}<0.0001 \\
<0.0001\end{array}$ & $\begin{array}{r}526 \\
6524\end{array}$ & $\begin{array}{l}26 \\
34\end{array}$ \\
\hline $4+$ & $\begin{array}{l}\text { HAS-BLED }>\mathrm{CHADS}_{2} \\
\text { HAS-BLED } \leq \mathrm{CHADS}_{2}\end{array}$ & $\begin{array}{r}7 \\
361\end{array}$ & $\begin{array}{l}57 \\
66\end{array}$ & $\begin{array}{r}3 \\
129\end{array}$ & $\begin{array}{r}0.0762 \\
<0.0001\end{array}$ & $\begin{array}{r}62 \\
2556\end{array}$ & $\begin{array}{l}53 \\
57\end{array}$ & $\begin{array}{r}13 \\
286\end{array}$ & $\begin{array}{r}0.0004 \\
<0.0001\end{array}$ & $\begin{array}{r}111 \\
4641\end{array}$ & $\begin{array}{l}26 \\
36\end{array}$ \\
\hline
\end{tabular}

${ }^{*} \chi^{2}$ tests comparing the proportion of patients treated with warfarin in the 60-69 years age group compared with the 80+ years age group.

$\mathrm{t} \chi^{2}$ tests comparing the proportion of patients treated with warfarin in the 70-79 years age group compared with the 80+ years age group.

observed in use of therapies in other areas of cardiovascular medicine. ${ }^{27}$ These have been attributed to a possible perceived lower risk of cardiovascular disease in women compared with men, leading to under-recording of risk factors and lower rates of prophylactic treatment in women. It may be that the same factors apply in the use of anticoagulation in patients with AF.

The factors that determine whether warfarin is prescribed in clinical practice are complex, and our study was not designed to investigate the reasons behind clinical decision making. Physicians often avoid anticoagulation in elderly patients due to fear of bleeding, fall risk, non-adherence and monitoring concerns. ${ }^{13-15}$ While the efficacy of warfarin in stroke prevention is established, warfarin has many limitations, including a narrow therapeutic index, slow onset and offset of action, multiple drug and food interactions, and a requirement for close laboratory monitoring of coagulation via the International Normalised Ratio (INR) and subsequent dose adjustments. ${ }^{28}$ Close monitoring necessitates regular clinic visits with increased financial burden and inconvenience to patients; thus, many eligible patients choose not to use warfarin. ${ }^{29}$ However, patient education and self-monitoring may promote better compliance and INR control among elderly patients with $\mathrm{AF}^{30}$

Unlike recent Swedish and Canadian studies, in this study, $\mathrm{CHADS}_{2}$ scores predicted anticoagulation use in a British population. $^{8}{ }^{9}$ The difference between these findings may reflect international variation in practice, or may be related to issues of study design: for instance, the present study was restricted to patients aged 60 years and over; and the Swedish study was smaller, so it cannot exclude associations of a similar magnitude to the present study.

The recent development of new anticoagulants, such as dabigatran, rivaroxaban and apixaban, represent potential new therapies for patients with AF that may circumvent many of the inconveniences of warfarin, such as regular INR checks, dietary restrictions and drug interactions. How new agents will be used in the management of elderly patients with $\mathrm{AF}$ in everyday practice remains to be established; however, recent NICE guidance recommends the use of dabigatran in atrial fibrillation under the licensed indication, which includes patients aged $>75$ years, and those aged $>65$ years with an additional risk factor. ${ }^{10}$

\section{Study limitations}

In this study, patients with at least one prescription for warfarin in their GP record were assumed to have been initiated on warfarin. The GPRD records prescriptions issued rather than dispensed, thus, it would not be possible to confirm whether a patient was taking the medication from an initial prescription alone. However, as this study aimed to investigate the

Table 4 Logistic regression models- CHADS2

\begin{tabular}{|c|c|c|c|c|c|c|}
\hline Variable & Unadjusted OR* & $95 \% \mathrm{Cl}$ & p Value & Adjusted OR* & $95 \% \mathrm{Cl}$ & p Value \\
\hline \multicolumn{7}{|l|}{ Men } \\
\hline $\mathrm{CHADS}_{2}=2 \dagger$ & 0.98 & 0.93 to 1.03 & 0.47 & 1.30 & 1.23 to 1.38 & $<0.0001$ \\
\hline $\mathrm{CHADS}_{2}=3 t$ & 0.98 & 0.92 to 1.05 & 0.62 & 1.35 & 1.26 to 1.45 & $<0.0001$ \\
\hline $\mathrm{CHADS}_{2}=4+\dagger$ & 0.97 & 0.90 to 1.06 & 0.53 & 1.44 & 1.32 to 1.57 & $<0.0001$ \\
\hline Goodness-of-fit & & & & & & 0.952 \\
\hline \multicolumn{7}{|l|}{ Women } \\
\hline $\mathrm{CHADS}_{2}=2 \dagger$ & 0.88 & 0.83 to 0.92 & $<0.0001$ & 1.21 & 1.14 to 1.28 & $<0.0001$ \\
\hline $\mathrm{CHADS}_{2}=3 t$ & 0.93 & 0.87 to 0.99 & 0.03 & 1.32 & 1.23 to 1.42 & $<0.0001$ \\
\hline $\mathrm{CHADS}_{2}=4+\dagger$ & 0.89 & 0.82 to 0.96 & 0.004 & 1.34 & 1.23 to 1.46 & $<0.0001$ \\
\hline Goodness-of-fit $\ddagger$ & & & & & & 0.575 \\
\hline
\end{tabular}


prescribing decision rather than the treatment, this will not have introduced major misclassification.

As discussed above, clinical practice is driven by other factors than are in the clinical guidelines such as patient preference, that may affect the decision as to whether warfarin is initiated, which are not recorded in GPRD. It might be that these factors have confounded the associations that we observed between age and sex and use of warfarin. Socioeconomic factors were not taken into account in our analysis, however, an earlier analysis of anticoagulation use in AF using general practice data suggests that these were not significant confounders of any association with anticoagulation use. ${ }^{17}$

While this study was able to look at the extent to which warfarin use was influenced by bleeding risk, as assessed using the HAS-BLED score, this tool does have limitations in terms of accuracy. ${ }^{20}$ Therefore, it is possible that we have not fully accounted for bleeding risk in our models. Nevertheless, we did find that higher HAS-BLED scores were associated with lower use of warfarin, suggesting that this tool does have reasonable utility as a means of adjusting for bleeding risk in this analysis.

\section{CONCLUSIONS}

Our analysis has demonstrated that age is much the strongest single predictor of whether or not anticoagulation is used in AF. The low use of warfarin in people aged 80 years is not explained by increased comorbidity or increased bleeding risk, since marked differences in use of warfarin were observed when we compared use in people aged $80+$ years with other ages, after we stratified by these factors, or adjusted for them. This suggests that there is genuine under-use of anticoagulation in the elderly. Strategies need to be developed to improve the uptake of anticoagulation in this age group.

Acknowledgements This study was sponsored by Boehringer Ingelheim International $\mathrm{GmbH}$. Writing and editorial assistance was provided by Lisa Buttle, PhD, of Ascot Medical Communications Consultancy, which was contracted by Boehringer Ingelheim International GmbH for these services. The authors meet the criteria for authorship as recommended by the International Committee of Medical Journal Editors (ICMJE), are fully responsible for all content and editorial decisions, and are involved at all stages of manuscript development. A poster entitled 'Too old for warfarin?' which included the preliminary results from this study has been presented at the Heart and Brain conference in Paris, March 2012. This study was funded by Boehringer Ingelheim Ltd.

Contributors Each author substantially contributed to the research. In detail: JM, SL and AS contributed to the conception and design of the study; AS contributed to data analysis; JM, AS and SL contributed to interpretation of the results; JM, AS, SL and LB drafted and revised the manuscript. All authors read and approved the final version of the manuscript.

Funding Boehringer Ingelheim.

Competing interests JM's department has received a consultancy fee from Boehringer Ingelheim Ltd for this work. JM has received payment for lectures from Boehringer. SL and AS are employees of Boehringer Ingelheim Ltd.

Ethics approval The study protocol was approved by the Independent Scientific Advisory Committee at the Medicines and Healthcare products Regulatory Agency (reference number 11_031).

Provenance and peer review Not commissioned; externally peer reviewed.

\section{REFERENCES}

1 Atrial Fibrillation Investigators. Risk factors for stroke and efficacy of antithrombotic therapy in atrial fibrillation: analysis of pooled data from five randomized controlled trials. Arch Intern Med 1994;154:1449-57.

2 Lip GYH, Lim HS. AF and stroke prevention. Lancet 2007;6:981-93.

3 Go AS, Hylek EM, Phillips KA, et al. Prevalence of diagnosed atrial fibrillation in adults: national implications for rhythm management and stroke prevention: the AnTicoagulation and Risk Factors in Atrial Fibrillation (ATRIA) Study. JAMA 2001;285:2370-5.

4 Tsang TS, Gersh BJ. Atrial fibrillation: an old disease, a new epidemic. Am J Med 2002;113:432-5.
5 Hart RG, Pearce LA, Aguilar MI. Meta-analysis: antithrombotic therapy to prevent stroke in patients who have nonvalvular atrial fibrillation. Ann Intern Med 2007:146:857-67.

6 Camm AJ, Kirchhof P, Lip GY, et al. Guidelines for the management of atrial fibrillation: the Task Force for the Management of Atrial Fibrillation of the European Society of Cardiology (ESC). Eur Heart J 2010;31:2369-429.

7 Lip GYH, Nieuwlaat R, Pisters R, et al. Refining clinical risk stratification for predicting stroke and thromboembolism in AF using a novel risk factor-based approach. The Euro heart Survey on AF. Chest 2010;137:263-72.

8 Carlsson AC, Wandell P, Sundquist K, et al. Differences and time trends in drug treatment of atrial fibrillation in men and women and doctors' adherence to warfarin therapy recommendations : A Swedish study of prescribed drugs in primary care in 2002 and 2007. Eur J Clin Pharmacol 2012. doi: 10.1007/ s00228-012-1322-6

9 Sandhu R, Bakal AB, Ezekowitz JA, et al. Risk stratification schemes, anticoagulation use and outcomes: the risk-treatment paradox in patients with newly diagnosed non-valvular atrial fibrillation. Heart 2011;97:2046-50.

10 National Institute for Health \& Clinical Excellence (NICE). Dabigatran etexilate for the prevention of stroke and systemic embolism in atrial fibrillation. Technology Appraisal TA249. March 2012. http://guidance.nice.org.uk/TA249/Guidance/pdf/English(accessed Mar 2012).

11 Darkow T, Vanderplas AM, Lew KH, et al. Treatment patterns and real-world effectiveness of warfarin in nonvalvular atrial fibrillation within a managed care system. Curr Med Res Opin 2005;21:1583-94.

12 Waldo AL, Becker RC, Tapson VF, et al. NABOR Steering Committee. Hospitalized patients with atrial fibrillation and a high risk of stroke are not being provided with adequate anticoagulation. J Am Coll Cardiol 2005;46:1729-36.

13 Hylek EM, D'Antonio J, Evans-Molina C, et al. Translating the results of randomized trials into clinical practice: the challenge of warfarin candidacy among hospitalized elderly patients with atrial fibrillation. Stroke 2006;37:1075-80.

14 Srivastava A, Hudson M, Hamoud I, et al. Examining warfarin underutilization rates in patients with atrial fibrillation: detailed chart review essential to capture contraindications to warfarin therapy. Thromb J 2008;6:6.

15 Chan PS, Maddox TM, Tang F, et al. Practice-level variation in warfarin use among outpatients with atrial fibrillation (from the NCDR PINNACLE program). Am J Cardiol 2011;108:1136-40.

16 Sinnaeve PR, Brueckmann M, Clemens A, et al. Stroke prevention in elderly patients with atrial fibrillation: challenges for anticoagulation. J Intern Med 2012;27:15-24.

17 De Wilde S, Carey IM, Emmas C, et al. Trends in the prevalence of diagnosed atrial fibrillation, its treatment with anticoagulation and predictors of such treatment in UK primary care. Heart 2006;92:1063-70.

18 Rash A, Downes $\mathrm{T}$, Portner $\mathrm{R}$, et al. A randomised controlled trial of warfarin versus aspirin for stroke prevention on octogenarians with AF (WASPO). Age Ageing 2007;36:151-6

19 Mant J, Hobbs R, Fletcher $\mathrm{K}$, et al. Warfarin versus aspirin for stroke prevention in an elderly community population with $\mathrm{AF}$ (the Birmingham AF Treatment of the Aged Study BAFTA): a randomised controlled trial. Lancet 2007;370:493-503.

20 Loewen P, Dahri K. Risk of bleeding with oral anticoagulants: an updated systematic review and performance analysis of clinical prediction rules. Ann Haematol 2011;90:1191-200.

21 García Rodríguez LA, Pérez Gutthann S. Use of the UK General Practice Research Database for pharmacoepidemiology. Br J Clin Pharmacol 1998;45:419-25.

22 Pisters $R$, Lane DA, Nieuwlaat $R$, et al. A novel user-friendly score (HAS-BLED) to assess one-year risk of bleeding in AF patients: The Euro heart Survey. Chest 2010;138:1093-100.

23 Ruigomez $A$, Johansson $S$, Wallander $M$, et al. Incidence of Chronic AF in general practice and its treatment pattern. J Clin Epidemiol 2002;55:358-63.

24 Murphy NF, Simpson CR, Jhund PS, et al. A national survey of the prevalence, incidence, primary care burden and treatment of atrial fibrillation in Scotland. Heart 2007:93:606-12.

25 Humphries KH, Kerr CR, Connolly SJ, et al. New-onset atrial fibrillation: sec differences in presentations, treatment, and outcome. Circulation 2001;103:2365-70.

26 Tsadok MA, Jackevicius CA, Rahme $\mathrm{E}$, et al. Sex differences in stroke risk among older patients with recently diagnosed atrial fibrillation. JAMA 2012;307:1952-8.

27 Horsfield $\mathrm{P}$, Teasdale S. Generating information from electronic patient records in general practice: a description of clinical care and gender inequalities in coronary heart disease using data from over two million patient records. Inform Prim Care 2003;11:137-44.

28 Ahmad Y, Lip GY. Stroke Prevention in Atrial Fibrillation: Where are We Now? Clin Med Insights Cardiol 2012;6:65-78.

29 Bungard TJ, Ghali WA, Teo KK, et al. Why do patients with atrial fibrillation not receive warfarin? Arch Intern Med 2000;160:41-6.

30 Khan TI, Kamali F, Kesteven $\mathrm{P}$, et al. The value of education and self-monitoring in the management of warfarin therapy in older patients with unstable control of anticoagulation. Br J Haematol 2004;126:557-64. 